\title{
Artigos
}

\section{A linguagem dramática e os processos de recepção nos cantos de aprendizagens diversificados na Educação Infantil na cidade de Curitiba - PR}

Resumo: Este trabalho reflete sobre o desenvolvimento da linguagem dramática na pequena infância associado aos processos de recepção nos cantos de aprendizagens diversificados na rede municipal de ensino na cidade de Curitiba PR. $\bigcirc$ texto também propõe evidenciar a importância do educador enquanto mediador de interações das crianças, nas brincadeiras das mesmas, sendo este um elemento fundamental, na evolução e desenvolvimento da dramaticidade. A investigação constatou que a linguagem dramática desempenha um papel significativo na educação infantil, fonte propícia para a criação artística, no qual elas são capazes de criar significado às suas experiências ao promover ações e fruições dramáticas.

Palavras-chave: Criança; Educação Infantil; Linguagem Dramática; Recepção.

\section{The dramatic language and the reception process in the corners of diversified learning in the Childhood Education in Curitiba city - PR}

\begin{abstract}
This work reflects on the development of dramatic language in early childhood associated with reception process in the corners of diversified learning in the municipal school system in Curitiba city - PR. The text also proposes to demonstrate the educator importance as mediator of children interactions, in the games of them, which is a key element, in the evolution and development of dramaticity. The research found that the dramatic language plays a significant role in childhood education, favorable source for artistic creation, in which they are able to create meaning to their experiences to promote action and dramatic fruitions. Keywords: Child; Childhood Education; Dramatic Language; Reception.
\end{abstract}

\footnotetext{
I Graduada no curso de Licenciatura em Teatro pela Universidade Estadual do Paraná/UNESPAR, campus de Curitiba II - Faculdade de Artes do Paraná e Licenciada em Pedagogia pela Faculdade Padre João Bagozzi. Pesquisa desenvolvida no Programa de Iniciação Científica entre os anos de 2012 e 2103 , orientada pelo professor Robson Rosseto. Professora da Educação Infantil e Anos Iniciais da Rede Municipal de Educação de Curitiba.

2 Doutorando no Programa de Pós-Graduação em Artes da Cena do Instituto de Artes da Universidade Estadual de Campinas/UNICAMP e Mestre em Teatro pela Universidade Estadual de Santa Catarina/UDESC. Professor do Curso de Licenciatura em Teatro da Universidade Estadual do Paraná/UNESPAR, campus de Curitiba II - Faculdade de Artes do Paraná.
} 
ste estudo busca analisar o desenvolvimento da linguagem dramática nas ações lúdicas com a pequena infância, a partir da mediação do professor dentro do espaço educativo. $O$ faz de conta que acontece naturalmente entre as crianças é uma forma de aprendizado sobre si e o mundo, e nesta experiência a dramaticidade torna-se um canal de expressão, permitindo que a mesma crie e transite em contextos fictícios, sem a exigência da divisão entre ator e público, como ocorre na Linguagem Teatral. Deste modo, as criações dramáticas infantis não têm como intenção conduzir a uma produção teatral, a um espetáculo elaborado e organizado, as crianças recriam sua realidade de forma espontânea através de sistemas simbólicos. Ao utilizar a imaginação e a fantasia, elas se desprendem do tempo-espaço em que se encontram para atribuir outros papéis a si, aos outros e a objetos diversos.

No drama, as crianças criam situações de comunicação e de comportamentos lúdicos livres e espontâneos, é um meio de conhecimento para elas, que permite que estas se coloquem por sua livre vontade em situações imaginárias. Nestes processos, a recepção ocorre de forma simultânea, portanto, serão pensados em conjunto com a dramaticidade da criança. As ideias aqui organizadas têm como objetivo pensar a criança enquanto fazedora e apreciadora nos processos dramáticos, além de ressaltar a importância da linguagem dramática desde a Educação Infantil.

O estudo pretende contribuir com reflexões sobre os elementos presentes no fazer dramático dos pequenos, onde o brincar surge como uma forma de experimentação estética cotidiana. Neste contexto, o adulto é compreendido como um articulador no desenvolvimento dramático, no qual auxiliam as crianças na elaboração e na produção de sentidos sobre a realidade vivida em circunstância ficcional. A pesquisa está pautada na necessidade de ampliar os conhecimentos sobre a linguagem dramática na Educação Infantil para privilegiar situações que envolvam vivências estéticas dentro do contexto educativo. A investigação foi realizada por meio de fontes bibliográficas ao discorrer sobre os elementos da pedagogia, da linguagem dramática e dos subsídios teóricos que compreendem o espaço enquanto elemento pedagógico.

Dentre as motivações que geraram o presente trabalho estão algumas inquietações vivenciadas especialmente por um dos pesquisadores deste artigo no decorrer da sua trajetória 
docente $^{3}$. Ao longo da experiência profissional foi possível constatar que em geral as instituições escolares, e por consequência os seus educadores, pouco privilegiam propostas dramáticas nas atividades educacionais como componente intrínseco do faz de conta da criança em suas práticas cotidianas.

$\mathrm{Na}$ última década alterações ocorreram no trabalho voltado para as crianças da Educação Infantil na cidade de Curitiba, como por exemplo, a frequente mobilização dos profissionais da educação em prol da oferta de um ensino qualitativo, em que o educar e o cuidar são prioridades na rotina de crianças da pequena infância. Nesta perspectiva, a linguagem dramática é considerada nas ações pedagógicas de forma sistematizada, que permite às crianças a imersão em situações do faz de conta, maneira de expressão que compreende a dramaticidade nas suas ações. Nesta concepção, cabe destacar, que ao longo do desenvolvimento das propostas dramáticas, a recepção dos acontecimentos ocorre de forma conjunta, "Assim, o contemplador, para desempenhar o papel que lhe cabe no evento, precisa colocar-se enquanto sujeito que age, pois a contemplação é algo ativo, e que cria, pois a sua atuação é necessariamente artística." (DESGRANGES, 2011, p.29)

Além das discussões sobre a atual concepção de criança, os espaços onde elas estão inseridas nos Centros Municipais de Educação Infantil (CMEIs) também receberam alterações importantes, uma delas foi a implantação dos cantos de aprendizagens diversificados dentro das salas de aula, que provocou novas relações entre adultos e crianças. Este espaço, o canto de aprendizagem, potencializa a capacidade expressiva da criança que envolve a experimentação/interpretação do mundo através da linguagem dramática, tornando possível assumir diferentes pessoalidades reais e/ou ficcionais.

Para iniciar uma reflexão sobre os apontamentos apresentados, o texto a seguir abordará as implicações do espaço educativo, especificamente sobre os cantos de aprendizagens, assinalando o importante papel do adulto mediador.

\section{O espaço educativo na Educação Infantil: possibilidades de ocupação}

Para a criança da pequena infância, o espaço educativo é um local de referência onde ela sente-se segura e acolhida. Por esta razão, os CMEIs que atendem crianças de 0 a 6 anos são organizados de forma criteriosa e alguns deles são denominados de cantos. O objetivo da participação e da interação das crianças nos cantos é a apropriação individual e coletiva de diferentes aprendizagens.

3 Integrante do quadro do magistério da Rede Municipal da cidade de Curitiba, onde iniciou em 2003 a sua prática profissional como educadora e atualmente é professora da Educação Infantil, desenvolvendo propostas pedagógicas com crianças da pequena infância. 
Cantos de atividades diversificadas são espaços de brincar organizados previamente por adultos ou por adultos e crianças, de modo que elas tenham várias possibilidades de atividades simultaneamente. É um momento de livre escolha das crianças, ou seja, elas decidem onde querem estar ou o que fazer. É uma atividade permanente, de frequência diária nos CMEls, CEls conveniados e escolas que ofertam educação infantil. (CURITIBA, 20 I0, p. 09)

Esses cantos contêm brinquedos e propostas de atividades temáticas que são dispostos com o objetivo de proporcionar o desenvolvimento da autonomia e o relacionamento interpessoal das crianças, com a mediação de um adulto capacitado. Os espaços são divididos em cantos temáticos com objetos que contemplam a faixa etária e o interesse das crianças, tais como: cozinha, materiais de construção, supermercado, jogos, livros, materiais escolares, dentre outros. Assim como, cantos que abordam temáticas trabalhadas previamente com as crianças, por exemplo, curiosidades e dinossauros. Nesta proposta, como a linguagem dramática pode ser desenvolvida nos cantos e de que forma contribui para instigar um olhar de espectador nas crianças?

As reflexões sobre esta questão serão aprofundadas na sequência deste trabalho, contudo, a compreensão histórica deste modelo de organização educativa, assim como, a sua inserção nas instituições de ensino básico do município se faz necessária, uma vez que, tal proposta reflete sobre a criança enquanto um sujeito ativo, protagonista de suas ações.

O entendimento de infância em nossa sociedade foi construído historicamente. Por séculos as crianças eram reconhecidas como adultos em miniaturas e realizavam tarefas como tais. Com o passar do tempo, novos modos de pensar surgiram sobre o conceito de infância e instituições de ensino passaram a existir para atender a esta demanda. A escola, em especial a da pequena infância teve na construção de sua identidade, inicialmente vínculos assistenciais e posteriormente o reconhecimento enquanto ambiente educativo. (BASSEDAS, 1999)

As relações entre crianças e espaço educativo também passaram por diferentes configurações, se no passado a presença da pedagogia tradicional inseria a criança em um espaço restritivo direcionado pelo adulto, atualmente prioriza-se a mobilidade e a participação infantil por meio de um contexto pautado na interação. (OLIVEIRA-FORMOSINHO, 2007)

Partindo destas concepções que concebem a criança enquanto sujeito histórico dentro de um contexto social, é válido ressaltar que o espaço necessário para a criança não se limita ao âmbito físico, sendo algo mais amplo e configurando-se como um local de experimentação. "É no espaço físico que a criança consegue estabelecer relações entre o mundo e as pessoas, transformando-o e um pano de fundo no qual se inserem emoções. Essa qualificação do espaço físico é o que o transforma em um ambiente." (HORN, 2004, p.28)

Desta forma, a alteração na configuração do modo de ocupação espacial de crianças não 
envolve somente o campo concreto dos mobiliários, de acordo com o filósofo Gaston Bachelard (1993) ele é mais profundo e complexo, pois permite a ampliação também do imaginário. "Que privilégio de profundidade há nos devaneios de criança!” (p. 35) O autor, ao debruçar-se sobre a poética contida no espaço reflete sobre a potência do imaginário sobre o mundo real e muito nos diz sobre como a criança reage sobre o espaço, pois, em um simples observar do cotidiano infantil, podemos ver o quão criativo e desafiador um pequeno espaço pode ser. Por exemplo, uma mesa aos olhos do real pode ser apenas um suporte para objetos, mas, se projetada à imaginação, facilmente se transformará em uma imensa caverna onde habitam monstros e mistérios.

O campo imaginativo de crianças pequenas é muito fértil, porém, é fundamental que o professor compreenda que o processo dramático é algo presente nas relações lúdicas, fato que exige do mesmo estar ciente das especificidades próprias desta etapa do ensino, para assim promover ações que ampliem o repertório artístico dos pequenos.

\section{O faz de conta pelos cantos e o professor que brinca}

O desenvolvimento da criança na faixa etária de 0 a 6 anos de idade é intenso e as apropriações das funções cognitivas e motoras são muito visíveis, se comparadas a outras fases do desenvolvimento humano. É durante a pequena infância que as crianças conquistam o domínio da fala e do pensamento. O processo da linguagem é primordial para que a criança avance etapas, no qual se apropria e faz uso do sistema simbólico.

Em consideração as diferentes fases da criança, este subitem busca refletir sobre a função dos cantos de aprendizagens diversificadas que, segundo o nosso estudo, se configura como mediadora entre professor e criança, a partir da afirmação de Lev Semenovich Vygotsky (2007), quando afirma que a relação entre o homem e o mundo se efetiva pela mediação.

Considerando as expressivas mudanças no desenvolvimento humano neste período, faz-se necessário destacar aqui dois momentos relevantes da pequena infância: o primeiro é a fase prélinguística tanto no pensamento quanto na linguagem, em que a criança tem uma relação mais prática agindo no ambiente sem a utilização da linguagem; o segundo é a fase posterior, quando a criança já apresenta o domínio do pensamento verbal e da linguagem formal.

Para se trabalhar com crianças nos cantos de atividades diversificados com a intervenção do adulto, de forma mais direta sobre as propostas de cada canto, é indicado a faixa etária que antecede os 3 anos de idade, no qual os espaços são apresentados como local de descobertas e de exploração. A divisão da faixa etária não é algo fixo e sim sugerido, uma vez que, as crianças na Educação Infantil estão em fase de construção de aprendizagens e apresentam trajetórias individuais próprias. 
Nesta faixa etária, faz-se necessária a mediação do educador/professor para que as crianças aprendam a brincar com os brinquedos, não adiantando apenas disponibilizá-los. É importante chamar a atenção das crianças para possibilidades de brincar e de explorar, além daquelas que já fazem de forma independente, em que a exploração cotidiana dos sentidos e a mediação constante do profissional promovam a atribuição de significados. (CURITIBA, 20 I 0, p. I 5)

Cabe ressaltar que o bebê ainda não utiliza as palavras como forma de interação com o meio, mas comunica-se corporal e sonoramente com os sujeitos a sua volta.

\begin{abstract}
Nesta fase de seu desenvolvimento, a criança, embora não domine a linguagem enquanto sistema simbólico, já utiliza manifestações verbais. O choro, o riso e o balbucio da criança pequena têm clara função de alívio emocional, mas também servem como meio de contato social, de comunicação difusa com outras pessoas. (OLIVEIRA, 1995, p.46)
\end{abstract}

O adulto ao trabalhar com esta faixa etária pode utilizar a imitação como um recurso de auxílio no desenvolvimento. Vera Lúcia Bertoni dos Santos (2011) explica que o ato de imitar é adquirido gradativamente pela criança que transita do imitar sem representar até a conquista da representação enquanto jogo simbólico, quando ela sente-se competente em representar um objeto ausente, ou seja, para brincar de faz de conta. A autora afirma que "a imitação é uma das fontes de representação. É a partir dela que os pequenos desde os primeiros dias de vida, estabelecem contato com o ambiente, com os seres vivos e os objetos do mundo real.” (p. 92)

Assim, o professor, enquanto sujeito mais experiente, tem a possibilidade de interagir no espaço, com a criança ao imitá-la em sua brincadeira. Neste sentido, o adulto tem a possibilidade de enriquecer, sistematicamente, a proposta. No caso do trabalho com crianças com faixa etária maior, a partir dos 3 anos de idade, novas relações entre professor, criança e espaço são estabelecidas. A partir desta fase as crianças já apresentam maior domínio da linguagem e do pensamento. Se antes o professor ocupava um papel de referência nas interações com o espaço, agora a criança já consegue estabelecer uma ocupação e exploração do espaço com uma maior independência.

"Por volta dos três anos surge um tipo de jogo mais complexo, que se caracteriza pela elaboração de cenas inteiras que vão ficando cada vez mais ricas e detalhadas.” (SANTOS, 2001, p. 94) Neste contexto, o adulto ao inserir-se enquanto participante, pode experimentar novas maneiras de se relacionar com as crianças por meio do brincar. No entanto, cabe salientar que a postura do professor não tem a intenção de direcionar a atividade, na realidade, ele se dispõe enquanto parceiro, assumindo os papéis propostos pelas crianças: se no canto da casinha a criança indicá-lo como filho, se posicionará como tal. 
Se segundo a pedagogia pós-crítica, os alunos precisam ter lugar para expressarem suas ideias, para emitirem suas vozes e os educadores radicais precisam criar condições para os alunos falarem, então o teatro pode ser este lugar. E o drama favorece a emissão das vozes, na medida em que a construção da narrativa se dá pela ação dos alunos, mediada pelo professor, assumindo ou não personagens [...]. (VIDOR, 2010, p. 26)

Tornar-se parceiro nas brincadeiras é um desafio para o profissional docente, uma vez que, na história da educação, a relação do professor em sala de aula esteve, por muito tempo, estruturada em uma organização hierarquizada. Do mesmo modo, o ato de brincar, muitas vezes, foi compreendido como um período de ócio desprovido de aprendizagens. Por estas razões, o posicionamento docente merece constantemente ser refletido, pois sua postura incide diretamente na formação da criança e também no que se espera desta formação. No decorrer da brincadeira do faz de conta, três aspectos necessitam destaque:

\begin{abstract}
A primeira delas é a função de "observador", na qual o professor procura intervir o mínimo possível, de maneira a garantir a segurança e o direito à livre manifestação de todos. A segunda função é de "catalisador", procurando através da observação, descobrir as necessidades e os desejos implícitos na brincadeira, para poder enriquecer o desenrolar de tal atividade. E, finalmente, de "participante ativo" nas brincadeiras, atuando como um mediador das relações que se estabelecem e das situações surgidas, em proveito do desenvolvimento saudável e prazeroso das crianças. (SANTOS, 200 I, p.98)
\end{abstract}

De acordo com a autora, o professor é um parceiro nas brincadeiras, planejando o desenvolvimento lúdico em ações cotidianas junto com as crianças pequenas. $\mathrm{Na}$ infância a experimentação do mundo é constante sendo fonte propícia para a criação artística e dentro das rotinas do espaço educativo é possível instaurar a suspensão do cotidiano, construindo assim, um estado poético, convidativo ao olhar, permitindo à criança transitar entre o fazer e o contemplar.

\title{
O jogo dramático como disparador dos processos de recepção
}

Ao adentrar em um espaço com crianças pequenas constata-se o interesse delas no brincar, especialmente pela dedicação e envolvimento das mesmas. Ao longo das praticas educativas é possível verificar que as crianças apresentam uma grande carga de dramaticidade nas suas interações entre os seus pares. O drama envolve brincadeiras e através dele é possível ao sujeito transitar entre o real e o imaginário, assumir várias vidas e interpretar o mundo ao seu redor. O drama na educação pode ser desencadeado por meio dos jogos dramáticos, que podem ser desenvolvidos nos cantos diversificados. 
O jogo dramático é uma parte vital da vida jovem. Não é uma atividade de ócio, mas antes a maneira da criança pensar, comprovar, relaxar, trabalhar, lembrar, ousar, experimentar, criar e absorver. O jogo é na verdade a vida. A melhor brincadeira teatral infantil só tem lugar onde oportunidade e encorajamento lhe são conscientemente oferecidos por uma mente adulta. Isto é um processo de "nutrição" e não interferência. (SLADE, 1978, p. I 8)

O jogo dramático é uma proposta pedagógica dramática fundamentada por Peter Slade que visa o desenvolvimento do drama em um enfoque processual, privilegiando o protagonismo da criança, em especial, a da pequena infância. Na prática, por meio da relação jogo-adulto-criança, o professor insere-se na brincadeira assumindo conscientemente outro papel. A criança, por sua vez, transita entre o mundo real e o faz de conta, sendo também espectadora e coautora da cena. Mesmo que ainda ela não se perceba como tal, acaba por contribuir com o seguimento da proposta dramática presente na concepção dos cantos. Assim, partindo do brincar, o adulto insere os elementos necessários para o desenvolvimento do contexto lúdico e próximo das crianças, e de forma paralela, aguça o olhar delas para a apreciação dos acontecimentos dramáticos ao seu redor. Neste sentido, o olhar da criança é aguçado para o drama, por exemplo, as alterações de corpo e voz dos colegas são percebidas para a composição de novas abordagens e inserção de personagens na atmosfera ficcional.

Assim sendo, na experiência do jogo dramático nos espaços privilegiados dos cantos, a criança observa as ações dos colegas, dos adultos e a partir destes elementos o professor tem a possibilidade de alçar materiais que privilegiem o processo de recepção, como espectadores.

\footnotetext{
O teatro é uma das mais antigas formas de expressão do homem, com eminente intuito estético, de apreciação sensível e comunicação. Nas festividades dionisíacas que marcam os primórdios das manifestações teatrais no Ocidente, todos participavam das danças, cantos, rituais e representavam "outros" que não a si próprios [...]. Quando alguns dos participantes afastam-se do grande grupo e passam a participar das práticas, mas desta vez não enquanto atuantes, e sim como observadores, distanciam-se daqueles que agem (atores) daqueles que veem (espectadores), e temos o princípio do teatro como o concebemos contemporaneamente. (FERREIRA, 2010, p. 31)
}

Se na origem do teatro participantes se distanciaram como atuante do acontecimento festivo para "ver" em outra perspectiva, caracterizando assim o espectador, o mesmo ocorre no âmbito da Educação Infantil. O "nascer" da criança espectadora advém da necessidade de observar o outro durante as atividades dramáticas, em geral por um curto período de tempo. Desta maneira, é importante apontar o uso de instrumentos para registrar as interações dos pequenos como 
fotografias e, em especial, as filmagens. As imagens são de grande valia, pois servem como recurso para subsidiar uma avaliação do processo dramático para o professor e do mesmo modo para a criança, uma vez que as considerações estimuladas a partir dos registros podem contribuir com reflexões sobre o desenvolvimento da linguagem dramática.

A recepção das crianças parte da observação do que lhes é mais próximo e o professor tem como possibilidade enriquecer o olhar delas por meio de questionamentos, assim, gradativamente a ideia de representação contida nas possibilidades em ser o outro vão sendo ampliadas através das análises do grupo dentro do contexto do ambiente educativo. Leitura esta que envolve a interpretação de códigos da cena, mas, sobretudo, permite que a criança espectadora assuma uma postura crítica e autônoma em suas interpretações e interferências quando diante da obra artística e ao participar de um processo dramático.

A intenção é promover um ambiente de participação democrática, seja pela disposição do mobiliário como também por ações que considerem o posicionamento ativo dos seus participantes. Os cantos de aprendizagem abarcam a concepção de que as propostas de ensino direcionadas à criança de hoje inferem, de forma direta, na formação do adulto do amanhã e de sua respectiva atuação social. Assim, a ludicidade presente nas brincadeiras infantis muito tem a dizer aos pesquisadores e estudiosos da educação, entretanto, infelizmente, a interação entre as crianças ao longo do tempo foi compreendida como algo de categoria inferior, em relação aos saberes eruditos selecionados pelos docentes. É válido ressaltar que a criança precisa ser ouvida e o conhecimento está no seu cotidiano, desta forma, se o adulto se dispuser a esta escuta, poderá proporcionar aprendizagens significativas considerando as especificidades dos pequenos.

O drama com crianças da pequena infância ainda é um desafio, especialmente pelo fato de muitos profissionais ainda compreenderem a dramaticidade na Educação Infantil enquanto produto, ocorrendo atividades deste gênero somente em datas festivas ou com montagens de peças temáticas, em situações de exposição. No entanto, as crianças estão em processo de amadurecimento, pouco aptas para exibições em público.

Desta maneira este artigo ressalta a importância e a necessidade da existência do drama na pequena infância em um caráter processual mediado por um ambiente propício para o desenvolvimento de múltiplas aprendizagens. Portanto, a organização intencional deste espaço é fundamental, uma vez que, a complexidade do tema extrapola as questões da disposição de materiais, traduzindo-se como elementos fomentadores das ações dramáticas das crianças e se apresentando como um campo fértil de ação pedagógica associado com o universo poético.

Os cantos de aprendizagens propõem a ação direta das crianças, em tal movimento o adulto é participante em diferentes níveis, tanto no distanciar quanto na aproximação intencional. A 
relevância da presença do adulto indica o exercício de aprimorar e propor novos desafios no faz de conta. Desta forma, a atitude docente merece atenção, pois o mesmo contribui para a construção de referenciais significativos aos pequenos.

É preciso validar as experiências estéticas presentes no próprio brincar da criança e também em vivências de apreciação dos processos dramáticos que surgem dentro do contexto educativo. Desta forma, a linguagem dramática na pequena infância permite que as crianças se apropriem progressivamente dos signos dramáticos de maneira lúdica e brincante e ao serem planejadas e previamente organizadas, acabam por privilegiar a interação, a intervenção e a criação de novos repertórios artísticos do grupo. 
Referências

BACHELARD, Gaston. A poética do espaço. Tradução de Antônio de Pádua Danesi. São Paulo: Martins Fontes, 1993.

BASSEDAS, Eulália. Aprender e ensinar na Educação Infantil. Porto Alegre: ARTMED, 1999.

CURITIBA. Prefeitura Municipal. Secretaria Municipal da Educação. Referenciais para estudo e planejamento na Educação Infantil: Cantos de Atividades Diversificadas na Educação Infantil, 2010.

DESGRANGES, Flávio. A pedagogia do teatro: provocações e dialogismo. 3. ed. São Paulo: Editora Hucitec, 2011.(Pedagogia do Teatro)

FERREIRA, Taís. A escola no teatro e o teatro na escola. Porto Alegre: Mediação, 2010.

HORN, Maria da Graça Souza. Sabores e aromas: a organização dos espaços na Educação Infantil. Porto Alegre: ARTMED, 2004.

OLIVEIRA-FORMOSINHO, Júlia. Pedagogias da Infância: dialogando com o passado: construindo o futuro. Porto Alegre: ARTMED. 2007.

SANTOS, Vera Lúcia Bertoni. Atenção Crianças Brincando! In: CUNHA, Suzana Rangel Vieira da. Cor, som e movimento: expressão plástica, musical e dramática no cotidiano da criança. 8. ed. Porto Alegre: Mediação, 2011.

SANTOS, Vera Lúcia Bertoni. Promovendo o desenvolvimento do faz de conta na Educação Infantil. In: CRAIDY, Carmem Maria. (Org). Educação Infantil: Pra que te quero? Porto Alegre: ARTMED, 2001.

SLADE, Peter. O jogo dramático infantil. São Paulo: Summus, 1978.

VIDOR, Heloise Baurich. Drama e teatralidade: o ensino do teatro na escola. Porto Alegre: Mediação, 2010.

VIGOTSKY, Lev Semenovich. A formação social da mente: o desenvolvimento dos processos psicológicos superiores. Tradução de José Cipolla Neto, Luís Silveira Menna Barreto e Solange Castro Afeche. 7. ed. São Paulo: Martins Fontes, 2007. 